\title{
ENTEROTOXIGENICIDADE DE ESPÉCIES DE AEROMONAS ISOLADAS EM DIFERENTES PONTOS DO FLUXOGRAMA DE ABATE DE FRANGOS*
}

\author{
F.N. Costa**1; O.D. Rossi Junior ${ }^{2}$ \\ 1Universidade Estadual do Maranhão, Departamento de Patologia, CP9, CEP 65075-240, São Luís, MA, Brasil. \\ E-mail: franciscacosta@cca.uema.br
}

\section{RESUMO}

\begin{abstract}
Com o objetivo de verificar a capacidade enterotoxigênica "in vivo" de cepas deAeromonasspp. isoladas em diferentes produtos e locais da planta de processamento de frangos, foram submetidas aos testes de inoculação intragástrica em camundongos lactentes e inoculação em alça ileal ligada de coelhos 75 cepas isoladas de penas, fezes, carcaças não evisceradas, evisceradas e resfriadas e água do pré-resfriamento. Das 75 cepas testadas, 31 (41,3\%) produziram enterotoxinas na prova de inoculação em alça ileal ligada de coelhos, sendo 9 (29\%) da espécieAeromonashydrophila, $9(29 \%)$ A. sobria, $6(19,4 \%)$ A. caviae, 4 (12,9\%) A. veronii, 1 (3,2\%) A. schubertii, 1 (3,2\%) A. trota e $1(3,2 \%)$ A. jandaei. Este estudo mostra que cepas de diferentes espécies de aeromonas são capazes de produzir enterotoxinas no teste in vivo, sugerindo riscos à saúde pública. O teste de inoculação intragástrica em camundongos lactentes não demonstrou a presença de cepas produtoras de enterotoxinas.
\end{abstract}

PALAVRAS-CHAVE: Aeromonas spp., abatedouro de frangos, enterotoxinas, inoculação em alça intestinal ligada de coelhos, teste de inoculação intragástrica em camundongos lactentes.

\begin{abstract}
ENTEROTOXICITY OF AEROMONAS SPECIES ISOLATED FROM DIFFERENT POINTS IN THE BROILERS SLAUGHTERING PROCESSING LINE. With the aim of verifying the capacity of in vivo production of enterotoxins of Aeromonas spp. strains isolated from products and at different places of the processing poultry plant, 75 strains isolated from feather, stool, pre-evisceration, post-evisceration, cooled carcass and "chilling" water samples were assayed by the ligated ileal loop test in rabbits and intragastric inoculation in suckling mice. From 75 strains analyzed, 31 $(41.3 \%)$ produced enterotoxins in the ligated ileal loop assay in rabbits, the breakdown being 9 (29.0\%) A. hydrophila, $9(29.0 \%)$ A. sobria, 6 (19.4\%)A. caviae, 4 (12.9\%)A.veronii, 1 (3.2\%)A.schubertii, $1(3.2 \%)$ A. trota and $1(3.2 \%)$ A. jandaei. This study showed that strains of different species of aeromonas are able to produce enterotoxins in in-vivo tests, suggesting a danger to public health. The test of intragastric inoculation in suckling mice did not show evidence of enterotoxin production.
\end{abstract}

KEY WORDS: Aeromonas spp., slaughtered poultry, enterotoxins, inoculation in ligated ileal loop assay in rabbits, test of intragastric inoculation in suckling mice.

\section{INTRODUÇÃO}

As aeromonas podem chegar aos alimentos pela água contaminada e fezes de animais que albergam a bactéria, ou ainda por pessoas portadoras ou doentes que manipulam alimentos (FIGURA; MARry, 1985). Segundo MAJEED et al. (1989) cepas de aeromonas se desenvolvem à temperatura de $5^{\circ} \mathrm{C}$, portanto a refrigeração das carcaças no abatedouro pode não impedir a multiplicação destes microrganismos. Cepas de $A$. hydrophila e A. sobria são capazes de produzir fatores de virulência, como enterotoxinas e hemolisinas em carnes estocadas à temperatura de $5^{\circ} \mathrm{C}$ (MAJEED et al., 1990). Além do fator temperatura influenciado a multiplicação e a sobrevivência das aeromonas nos alimentos, outros devem ser considerados, como concentração de sal, pH e atmosfera. Estes fatores interagem influenciando a multiplicação e sobrevivência das

\footnotetext{
${ }^{2}$ Universidade Estadual Paulista, Departamento de Medicina Veterinária Preventiva, Jaboticabal, SP, Brasil. *Auxílio Financeiro FAPESP.

**Bolsa CAPES.
} 
aeromonas em alimentos armazenados em baixas temperaturas (KNOCHEL; JEPPESEN, 1990).

As aeromonas podem produzir um número significativo de fatores de virulência, incluindo endotoxinas, enterotoxinas, adesinas, citotoxinas, hemolisinas, lipases e proteases, as quais são capazes dedesencadear uma série de distúrbios (CAHILL,1990).

Aimportância realdosfatores devirulênciaainda não está bem esclarecida, pois nem todas as cepas que os possuem são patogênicas e, para que haja o quadro de gastrenterite, tem quehavera combinaçãodacepa produtora desses fatores com as condições predisponentes, como a idade e o estado imunológico do hospedeiro, sendo mais propensas às crianças com menos de dois anos, adultos com mais de cinqüenta anos e pessoas imunocomprometidas (KIROV; BRODRIBB, 1993).

RAlletal. (1998) testaramcepas de A. sobria, A.caviae e $A$. hydrophila, isoladas de amostras de peixe quanto à capacidade de produção de enterotoxina citotônica, em testes in vivo e in vitro e verificaram que $17 \%$ das cepas de A. sobria e $10 \%$ das A. caviae produziram enterotoxinas no teste in vivo e que as cepas de A. hydrophila não produziram enterotoxinas neste teste. No testeinvitro, ascepasnãoproduziram enterotoxinas.

Rossi JúNIOR et al. (2001) testaram 18 cepas de $A$. hydrophila e 65 de A.caviae, isoladas dediferentes produtos e locais do fluxograma de abate de bovinos, quanto a capacidade de produção de enterotoxinas in vivo, utilizandoostestes deinoculaçãoemalçaileal ligada de coelhos e intragástrica em camundongos lactentes e verificaram que $3(16,7 \%)$ das cepas de A.hydrophila e1 $(1,5 \%)$ de A.caviae produziram enterotoxinas.

Diante do exposto, o objetivo da pesquisa foi verificar, in vivo, utilizando os testes de inoculação intragástrica em camundongos lactentes e em alça ileal ligada de coelhos, a capacidade de produção de enterotoxinas por diferentes espécies de Aeromonas isoladas em vários pontos e produtos da linha de processamento de frangos.

\section{MATERIAL E MÉTODOS}

As cepas de aeromonas isoladas de amostras de penas, fezes, carcaças de frangos não evisceradas, evisceradaseresfriadaseáguadopré-resfriamentodeum abatedouro de frango submetido a controle higiênicosanitário permanente, foram repicadasemcaldotripticase soja (TSB) e incubadas a $28^{\circ} \mathrm{C}$ por $24 \mathrm{~h}$. Em seguida, alíquotas de $0,1 \mathrm{~mL}$ foram transferidas para frascos contendo $20 \mathrm{~mL}$ de TSB adicionado de $0,6 \%$ de extrato de levedura(BuRKE et al.,1981). Após $24 \mathrm{~h}$ de incubação a $37^{\circ}$ C(SERAFIM et al., 1994) centrifugou-se as culturas a 8.000 rpm por $20 \mathrm{~min}$ a $4^{\circ} \mathrm{C}$. Os sobrenadantes obtidos foram esterilizados por filtração em membranas de $0,45 \mathrm{~mm}$, obtendo-se os extratos para inoculação intragástrica em camundongos lactentes e em alça ileal ligada de coelhos. Paraa produçãodosextratosforamutilizadasumtotalde 75 cepas de aeromonas, sendo 19 da espécie Aeromonas hydrophila, 18 de A. sobria, 20 de A. caviae, 12 de A.veronii, 3 de $A$. schubertii, 2 de $A$. trota e 1 de $A$. jandaei.

Para o teste em alça intestinal ligada foram utilizados coelhos albinos da raça Norfolk 2000, com peso entre 1.500 e $2.000 \mathrm{~g}$. Após anestesia com cloridrato de ketamina e cloridrato de xilazina nas dosagens de 20 $\mathrm{mg} / \mathrm{kg}$ e $2 \mathrm{mg} / \mathrm{kg}$, respectivamente, as alças intestinais foram expostas por laparotomia e o conteúdo do íleo removido. Após lavagem das alças com solução fisiológica estéril, estas foram divididas em segmentos de aproximadamente $5 \mathrm{~cm}$, por meio de ligaduras com fio de algodão estéril. Volumes de $1 \mathrm{~mL}$ dos filtrados foram injetados em segmentos alternados, suturando-se em seguida o abdome. Para o controle positivo foi inoculado filtrado de cepa de E. coli enterotoxigênica e para o negativo caldo tripticase soja estéril (AвEYTa Junior et al., 1986; SingH; SANYAL 1992). Após $18 \mathrm{~h}$, os coelhos foram sacrificados e as alças intestinais examinadas quanto à presença de dilatação e acúmulo de fluido. Para cada um dos segmentos calculou-se a relação volume do líquido/ comprimento, sendo o teste considerado positivo quando essa relação se mostrava pelo menos quatro vezes maior que a encontrada no controle negativo em dois coelhos. Nos casos de resultados antagônicos o teste foi repetido em pelo menos mais um animal.

No teste em camundongos lactentes foram utilizados, para cada uma das cepas, 3 camundongosalbinos Suíços com idade entre 3 e 5 dias. A cada $1 \mathrm{~mL}$ de sobrenadante estéril foram adicionadas duas gotas de solução de azul de Evans a 1\%, e 0,1 mL dessa mistura foram inoculados, via intragástrica, em cada um dos camundongos lactentes. Os animais foram mantidos a $28^{\circ} \mathrm{C}$ por $4 \mathrm{~h}$ e, em seguida, eutanaziados com éter. Tanto os intestinos como as carcaças foram pesados imediatamente. Considerava-se positivo quando a proporção entre peso do intestino e peso de carcaça era de, no mínimo, 0,080 em pelo menos 2 camundongos. No controle positivo os 3 camundongos receberam $0,1 \mathrm{~mL}$ de sobrenadante estéril de uma cepa de Escherichia coli enterotoxigênica e os controles negativos $0,1 \mathrm{~mL}$ de caldo tripticase soja estéril (DEAN et al., 1972; KAPER et al., 1981; SinGH; SANYAL, 1992).

O presente estudo foi aprovado pela Comissão de Ética e Bem Estar Animal (CEBEA) da FCAV/UNESP sob protocolo n. 008716-07.

\section{RESULTADOS E DISCUSSÃO}

Os percentuais de cepas produtoras de enterotoxinas mostrados na Tabela 1 são superiores aos descritos por FIGURA; MARRI (1985) que verificaram 
que $13,3 \%$ das cepas de $A$. hydrophila e nenhuma $A$. caviae isoladas de carne de suíno produziram enterotoxinas e aos deKIrov etal.(1990) queverificaram que cepas de $A$. hydrophila isoladas de carcaças de frango não foram enterotoxigênicas.MAJEED etal.(1989) observaram que 21 (65,6\%) cepas de A. hydrophila, 12 (75\%) de A. sobria e somente 1 (5\%) de A. caviae produziram enterotoxinas. FreITAS etal.(1993) demonstraram que as discrepâncias entre os percentuais de cepas enterotoxigênicas verificados em diversas pesquisas eram decorrentes de diferenças entre as propriedades devirulência das amostrasisoladas em regiões geográficas diferentes. Os achados da presente pesquisa são preocupantes, uma vez que $41,3 \%$ das cepas mostraram potencial enterotoxigênico e as espécies $A$. hydrophila, A. caviae e A. sobria, consideradas pela literatura como as mais patogênicas também foram isoladas das fezes das aves.

Pode ser observado na Tabela 1 também que o teste de inoculação intragástrica em camundongos lactentes não permitiu evidenciar cepas produtoras de enterotoxinas. Este achado está de acordo com os dados da pesquisa realizada por HAQUE et al. (1996) que, ao submeterem cepas de aeromonas isoladas de casos clínicos de diarréia e de amostras ambientais ao teste de inoculação intragástrica em camundongos lactentes, verificaram que cepas sabidamente patogênicas deram resultados negativos.
Estes resultados sugerem que estas são uma importante fonte de contaminação de aeromonas para as carcaças e, apesar do rígido controle higiênicosanitário adotado na indústria, as carcaças resfriadas e prontas para o consumo podem chegar ao consumidor contaminadas por este microrganismo. Os riscos à saúde pública devem ser considerados, pois algumas espécies têm sido associadas a casos de diarréia e gastroenterites.

No teste de inoculação em alça intestinal ligada de coelhos(Tabela2)constatou-sequeosvaloresobtidosna relação entre o volume e o comprimento da alça intestinal variaram de 0,62 a 1,80, em 9 cepas de $A$. hydrophila. Quanto as cepas de A. sobria 9 foram produtoras de enterotoxinas com valores variando de 0,22 a 2,18 e em cepas de A. caviae variaram de 0,21 a 1,84. Ainda com relação aos resultados apresentados na Tabela 2 , observa-se também que 4 cepas de $A$. veronii, uma de $A$. schubertii, A. trotae $A$. jandaei produziram líquido na luz intestinal de coelhos com relações que variaram de 0,14 a1,80,0,33 a 1,60,0,41 a1,09e0,25a 1,30, respectivamente. Quanto aos achados apresentados na Tabela 2, referentes às espécies A.hydrophila $\mathrm{e}$ A. caviae, osvaloressão semelhantes aos de Rossi JúnIor et al. (2001) que encontraram no teste de inoculação em alça intestinal ligada de coelhos valores que variaram de 1,20 a 2,10 para $A$. hydrophila, e para A. caviae valor mínimo de 0,78 e máximo de 1,30 e os controles negativos 0,04 e 0,08.

Tabela 1 - Resultados dos ensaios de enterotoxigenicidade em alça ligada de coelhos e camundongos recém nascidos com diferentes espécies de Aeromonas, Jaboticabal, SP.

\begin{tabular}{|c|c|c|c|c|}
\hline \multirow[t]{2}{*}{ Espécies inoculadas } & \multirow{2}{*}{$\begin{array}{l}\text { № de cepas } \\
\text { examinadas }\end{array}$} & \multicolumn{2}{|c|}{ № de cepas positivas } & \multirow[t]{2}{*}{ Origem das cepas } \\
\hline & & $\begin{array}{c}\text { Teste em camun- } \\
\text { dongos lactentes } \\
(\%)\end{array}$ & $\begin{array}{c}\text { Teste em alça } \\
\text { ileal ligada de } \\
\text { coelhos }(\%)\end{array}$ & \\
\hline A. hydrophila & 19 & 0 & $9 / 19\left(47,3^{2}\right)$ & $\begin{array}{l}\text { Penas, fezes, carcaças evisceradas e } \\
\text { não evisceradas, água do pré-res- } \\
\text { friamento, e carcaças resfriadas }\end{array}$ \\
\hline A. sobria & 18 & 0 & $9 / 18(50,0)$ & $\begin{array}{l}\text { Penas, fezes, carcaças evisceradas e } \\
\text { não evisceradas, água do pré-res- } \\
\text { friamento e carcaças resfriadas }\end{array}$ \\
\hline A. caviae & 20 & 0 & $6 / 20(30,0)$ & $\begin{array}{l}\text { Penas, fezes, carcaças evisceradas e } \\
\text { não evisceradas, água do pré-res- } \\
\text { friamento e carcaças resfriadas }\end{array}$ \\
\hline A. veronii & 12 & 0 & $4 / 12(33,3)$ & $\begin{array}{l}\text { Penas, fezes, carcaças não evisceradas } \\
\text { e carcaças resfriadas }\end{array}$ \\
\hline A. schubertii & 3 & 0 & $1 / 03(33,3)$ & Carcaça não eviscerada \\
\hline A. trota & 2 & 0 & $1 / 02(50,0)$ & Água do pré-resfriamento \\
\hline A. jandaei & 1 & 0 & $1 / 01(100,0)$ & Carcaça não eviscerada \\
\hline Total & 75 & 0 & $31 / 75\left(41,3^{1}\right)$ & \\
\hline
\end{tabular}

${ }^{1}$ Porcentagem de cepas testadas em relação ao total de cepas espécie tipificadas.

${ }^{2}$ Porcentagem de cepas positivas em relação ao total de cepas testadas para cada uma das espécies 
Tabela 2 - Valores positivos encontrados nas relações entre volume e comprimento de alça intestinal ligada de coelhos, relativos ao teste para verificação da produção de enterotoxinas, segundo as espécies de aeromonas inoculadas.

\begin{tabular}{|c|c|c|c|}
\hline \multirow{2}{*}{$\begin{array}{l}\text { Espécies } \\
\text { inoculadas } \\
\text { A. hydrophila }\end{array}$} & \multirow{2}{*}{$\begin{array}{c}\text { № de cepas } \\
\text { positivas } \\
\\
9\end{array}$} & \multicolumn{2}{|c|}{$\begin{array}{c}\text { Teste em alça intestinal } \\
\text { ligada de coelhos. } \\
\text { Valores da relação } \\
\text { volume/comprimento }\end{array}$} \\
\hline & & 0,62 & - 1,33 \\
\hline & & 1,27 & - 1,80 \\
\hline & & 0,86 & - 1,08 \\
\hline & & 0,90 & - 1,45 \\
\hline & & 0,88 & - 1,00 \\
\hline & & 0,62 & - 0,90 \\
\hline & & 1,09 & - 1,33 \\
\hline & & 1,38 & - 1,53 \\
\hline & & 0,80 & - 1,07 \\
\hline \multirow[t]{9}{*}{ A. sobria } & 9 & 0,93 & - 1,33 \\
\hline & & 0,62 & - 1,40 \\
\hline & & 0,72 & - 1,07 \\
\hline & & 0,22 & - 1,08 \\
\hline & & 0,90 & - 1,33 \\
\hline & & 0,83 & - 1,38 \\
\hline & & 0,80 & - 1,27 \\
\hline & & 1,87 & - 2,18 \\
\hline & & 1,00 & - 1,10 \\
\hline \multirow[t]{6}{*}{ A. caviae } & 6 & 1,33 & - 1,45 \\
\hline & & 0,87 & - 1,45 \\
\hline & & 0,64 & - 1,84 \\
\hline & & 0,71 & - 1,40 \\
\hline & & 0,21 & - $\quad 0,85$ \\
\hline & & 0,25 & - 1,40 \\
\hline \multirow[t]{4}{*}{ A. veronii } & 4 & 0,54 & - 0,80 \\
\hline & & 0,87 & - 1,80 \\
\hline & & 0,14 & - 0,83 \\
\hline & & 0,60 & - 0,88 \\
\hline A. schubertii & 1 & 0,33 & - 1,60 \\
\hline A. trota & 1 & 0,41 & - 1,09 \\
\hline A. jandaei & 1 & 0,25 & $\begin{array}{l}-\quad 1,30 \\
\end{array}$ \\
\hline \multicolumn{2}{|c|}{ Controle negativo } & \multicolumn{2}{|c|}{0,012 a $0,028^{2}$} \\
\hline
\end{tabular}

${ }^{1}$ Valores obtidos a partir da inoculação em dois coelhos. ${ }^{2}$ Valores mínimo e máximo obtidos na inoculação dos coelhos utilizados nos testes.

Deve-se considerar como produtoras de enterotoxinas as cepas cujos valores das relações volume/comprimento forem, no mínimo, quatro vezes maior que o controle negativo (KAPER et al., 1981; AbeYta Júnior et al., 1986). Portanto, pelos dados da tabela deve-se considerar como positivos valores acima de 0,048 e os valores encontrados são superiores (mínimo de 0,14 e máximo de 2,18), caracterizando que houve um grande acúmulo de líquido na alça intestinal ligada de coelhos, possivelmente pela capacidade de produção de enterotoxinas das cepas inoculadas.

Os achados mostram que cepas de aeromonas são capazes de produzir enterotoxinas no teste in vivo, evidenciando um risco potencial à saúde pública.

\section{AGRADECIMENTOS}

\section{CAPES E FAPESP.}

\section{REFERÊNCIAS}

Abeyta Júnior, C.; Kaysner. C.A.; Wekel, M.M.;Sullivan, J.J.; Stema, G.N. Recovery of Aeromonas hydrophila from oystersimplicated in an outbreak of foodborneillness. Journal of Food Protection, v.49, p.643-646, 1986.

BurKe, V.; R obINSON,J.; A tKINSON,H.M.; D IBLEY, M.;B ERRY, R.J.; GraceY, M. Exotoxins of Aeromonas hydrophila.AJEBAK, v.59, n.6, p.653-761, 1981

CAHILl, M.M. Virulence factors in motileAeromonas species. A review. Journal Applied Bacteriology, v.69, p.1-16, 1990.

Dean, A.G.; Ching, Yi-C.; Williams, R.G.; Harden, L.B. Test for Escherichia coli enterotoxin using infant mice: Application in a study of diarrhea in children in Honolulu. Journal of Infection Diseases, v.125, n.4, p.407411, 1972.

Figura, N.; Marry, L. Isolation of Aeromonas species from animals. European Journal Clinical Microbiology, v.4, n.3, p.354-355, 1985.

Freitas, A. C.; Milhomem, A.M.; Nunes, M.P.; Ricciardi, I.D. Virulence factors produced by Aeromonas hydrophila strains isolated from different sources. Revista de Microbiologia, v.24, n.3, p.168-174, 1993.

Haque, Q.M.; Sugiyama, A.; Inade, Y.; Midorikawa, Y.; YAMAUCHI, T. Diarrheal an environmental isolates of Aeromonas spp. produce a toxin similar to shigalike toxin 1. Current Microbiology, v.32, p.239-245, 1996.

KAPER,J.B.;L OCKMAN, H.; COLwelL, R.R.Aeromonashydrophila: ecology and toxigenicity of isolates from a estuary. Journal of Applied Bacteriology, v.50, p.359-377, 1981.

KIROV, S.M.; B RODRIBB, F. Exotoxin production by Aeromonas spp in foods. Letters in Applied Microbiology, v.117, p.208-211, 1993.

KIrov, S.M.; Anderson, M.J; McMeekin, T.A. A note form Aeromonas spp. from chickens as possible food-borne pathogens. Journal of Applied Microbiology, v.68, p.327334, 1990.

KNOCHEL, S.; JePpesen, C. Distribution and characteristics of Aeromonas in food and drinking water in Denmark. International Journal of Food Microbiology, v.10, p.317$322,1990$.

Majeed, K.N.; Egan, A.F.; MacRae, I.C. Enterotoxigenic aeromonads on retail lamb meat and offal. Journal of Applied Bacteriology, v.67, p.165-170, 1989. 
Majeed, K.N.; Egan, A.F.; MacRae, I.C. Production of exotoxins by Aeromonas spp at $5^{\circ} \mathrm{C}$. Journal of Applied Bacteriology, v.69, p.332-337, 1990.

Rall, V.L.M.;Iaria, S.T.; Heidtmann,S.;Pimenta,F.C.;G amba, R.C; Pedroso, D.M.M. Aeromonas species isolated from pintado fish (Pseudoplatysma sp): virulencefactors and drug susceptibility. Revista de Microbiologia, v.29, n.3, p.222-227, 1998.

Rossi JÚNIOR, O.D.; Amaral, L.A.;NAder Filho, A.; SCHOCKENItURRINo, R.P. Enterotoxigenicidade de cepas de Aeromonas sp. isoladas em diferentes pontos do fluxograma de abate bovino. Arquivos Brasileiro de Medicina Veterinária e Zootecnia, v.53, n.5, p.589-594, 2001.
Serafim, M.B.; Piton, M.A.J.; Colli, I.A.G.; Castro, A.F.P. Enterotoxin of Aeromonas sp. some culture conditions which affect its production. Revista de Microbiologia, São Paulo, v.25, n.4, p.220-224, 1994.

SingH, D.V.; SANYAL, S.C. Enterotoxicity of clinical and environmental isolates of Aeromonas spp. Journal of Medical Microbiology, v.36, p.269-272, 1992.

Recebido em $17 / 4 / 06$

Aceito em 13/10/06 